\title{
Production and Viability of Pollen and Pollen-Ovule Ratios in Four Rabbiteye Blueberry Cultivars
}

\author{
Patricio A. Brevis ${ }^{1}$ and D. Scott NeSmith ${ }^{2}$ \\ Department of Horticulture, University of Georgia, Griffin Campus, Griffin, GA 30223 \\ Hazel Y. Wetzstein'2 \\ Department of Horticulture, University of Georgia, Athens, GA 30602 \\ Dorothy B. Hausman ${ }^{3}$ \\ Department of Foods and Nutrition, University of Georgia, Athens, GA 30602
}

\begin{abstract}
AdDitional INDEX wORDs. Vaccinium ashei, Ericaceae, tetrad germination, buzz pollination, poricidal anther
Aвstract. Fruit set of rabbiteye blueberries (Vaccinium ashei Reade) can be pollen-limited under certain conditions. The objective of this study was to determine production, release, and viability of pollen, as well as pollen-ovule ratios in the rabbiteye blueberry cultivars Austin, Brightwell, Climax, and Tifblue. In vitro tetrad germination varied among genotypes, although, values were high $(\geq 80 \%)$ in all cultivars. Pollen viability does not seem to contribute to reproductive failure in the cultivars studied. Total pollen production per flower averaged 8434 tetrads across all cultivars. On a per ovule basis, pollen production was very low relative to other xenogamous species. The low pollen-ovule ratio of rabbiteye blueberry $(\approx 400)$ may be an indicator of the high efficiency of its pollen dispensing mechanism. Total pollen production varied among cultivars. Furthermore, a significant difference in pollen release was found between two cultivars with similar total pollen production per flower. The possible mechanism regulating pollen release in these cultivars is discussed.
\end{abstract}

It is common for xenogamous (outcrossed), hermaphroditic flowering plants to produce more flowers and ovules than fruits and seeds (Bawa and Webb, 1984). Two explanations for this pattern are 1) maternal resources available for fruit and seed maturation are limited, or 2) pollen delivery to the stigma is insufficient (Sutherland, 1987). Pollen limitation of seed set is widely reported in angiosperms (Burd, 1994; Larson and Barret, 2000).

According to Shutak and Marucci (1966), highbush blueberries (Vaccinium corymbosum L.) are capable of setting fruit for almost $100 \%$ of their flowers, and fruit set levels as high as $80 \%$ are required for adequate commercial production. In contrast, poor fruit set is one of the most important horticultural problems of the rabbiteye blueberry (V. ashei) industry (Scherm et al., 2001). For instance, estimates of fruit set as low as $8 \%$ to $10 \%$ have been recorded for the widely planted rabbiteye cultivar Tifblue under field conditions in the southeastern United States (Lyrene and Crocker, 1983; NeSmith and Adair, 2004). Rabbiteye blueberries have a limited degree of self-fertility and require cross-pollination with another rabbiteye cultivar (El-Agamy et al., 1981). In general, self-infertile plants exhibit more pollen limitation than those with the capacity to self-fertilize, because self-pollen cannot contribute to reproductive success (Burd, 1994; Larson and Barret, 2000). Therefore, it is likely that fruit set of rabbiteye blueberries can be pollen-limited, rather than resource-limited, under certain conditions.

Received for publication 2 Sept. 2005. Accepted for publication 11 Dec. 2005. A contribution of the Univ. of Georgia Agricultural Experiment Stations, Georgia Station, Griffin. This research was supported, in part, by state and Hatch Act funds allocated to the Georgia Agricultural Experiment Stations.

${ }^{1}$ Graduate Research Assistant. Current address: Dept. of Horticulture, Michigan State Univ., East Lansing, MI 48824.

${ }^{2}$ Professor.

${ }^{3}$ Associate Research Scientist.
Several studies have examined the role of pollen quality on the fruiting capacity of blueberry. Pollen germination is affected by genotype (Eaton, 1966; Goldy and Lyrene, 1983; Lang and Parrie, 1992), and low pollen viability has been linked to poor fruit set in some highbush blueberry cultivars (Brewer and Dobson, 1969; Stushnoff and Hough, 1968). Moreover, Vander Kloet (1983) reported significant correlation between pollen viability and fruit quality parameters such as fruit size. Pollen viability studies in rabbiteye blueberry are quite limited (Cockerham and Galleta, 1976), so the role of pollen quality on fruit set remains unclear.

High pollen production is desirable for bee-pollinated plants. Since bees constantly groom their bodies and pack pollen into scopae (specialized pollen-transporting areas), most of the pollen collected by these pollinators is unavailable for pollination (Harder and Wilson, 1997; Thorp, 2000). Therefore, pollen must be produced in abundance to compensate for its inefficient transfer by bees, and in fact, xenogamous flowers produce more pollen (on a per ovule basis) than those of autogamous (selfpollinated) plants (Cruden, 1977). Blueberry is a bee-pollinated crop, and cross-pollination is beneficial for fruit quality and yield. Although knowledge of pollen production and release could help to identify cultivars with outstanding performance as pollinizers, these variables have received little attention in Vaccinium L. section Cyanococcus A. Gray. Brewer and Dobson (1969) reported that 'Jersey', a highbush blueberry cultivar with problems of low fruit set, released less pollen than 'Rubel.' Reader (1977) quantified total pollen production per flower of $V$. myrtilloides Michx. growing in a peat bog. To our knowledge, there is no such information available for rabbiteye blueberries. The objective of this research was to determine viability, production, and release of pollen in selected rabbiteye blueberry cultivars. Additionally, the pollen-ovule ratio of rabbiteye blueberry was estimated to relate its pollen production to that of other flowering plants with similar breeding systems. 


\section{Materials and Methods}

Plant material and locations. Three-year-old blueberry plants of the rabbiteye cultivars Austin, Brightwell, Climax, and Tifblue were obtained from the blueberry breeding program at the Univ. of Georgia Griffin Campus. Plants were grown in 19-L containers using pine bark as a growing medium. Seven plants of each cultivar were kept from 6 Nov. 2001 until near the beginning of bloom in the following spring at Griffin and Alapaha in order to provide varied pre-bloom environments. Griffin is located in central Georgia, where the USDA plant hardiness zone is $7 \mathrm{~b}$. Alapaha is located in southern Georgia (hardiness zone 8 a) and is more representative of the blueberry producing area of the state.

Pollen production AND viability. Near the beginning of bloom, plants were brought into a greenhouse at the Univ. of Georgia Athens Campus to evaluate total pollen production and viability. Plants from Alapaha were moved into the greenhouse on 7 Mar. 2002, and those from Griffin were moved 2 weeks later. Plants were fertilized with a $15 \mathrm{~N}-3.9 \mathrm{P}-10 \mathrm{~K}$ controlled-release fertilizer and watered as needed.

Pollen viability was assessed by determining germination of tetrads in vitro. Germination tests were conducted using fresh pollen collected on the same day. Experimental units consisted of pollen samples extracted from 15 flowers at the stage of anthesis collected from the seven plants of each cultivar at each location. Pollen was extracted in the laboratory by rolling a flower between the thumb and index finger over a petri dish. The pollen germination medium consisted of $100 \mathrm{mg} \cdot \mathrm{L}^{-1} \mathrm{H}_{3} \mathrm{BO}_{3}, 300 \mathrm{mg} \cdot \mathrm{L}^{-1}$ $\mathrm{Ca}\left(\mathrm{NO}_{3}\right)_{2} \cdot \mathrm{H}_{2} \mathrm{O}, 200 \mathrm{mg} \cdot \mathrm{L}^{-1} \mathrm{MgSO}_{4} \cdot 7 \mathrm{H}_{2} \mathrm{O}, 100 \mathrm{mg} \cdot \mathrm{L}^{-1} \mathrm{KNO}_{3}$, and $10 \%$ sucrose (Garvey and Lyrene, 1987 ). Pollen from each sample was suspended in the germination medium at a rate of $100 \mathrm{mg} \cdot \mathrm{L}^{-1}$, and $200-\mu \mathrm{L}$ aliquots of stirring suspension were added to six wells of a culture plate (model Microtest III; Falcon, Lincoln Park, N.J.). After $2 \mathrm{~h}$ of incubation in a dark growth chamber at $24^{\circ} \mathrm{C}$, pollen germination was examined using an inverted microscope (Nikon, Garden City, N.Y.). Pollen grains were considered germinated if pollen tube extension was greater than the diameter of the tetrad (Lang and Parrie, 1992). The number of tetrads containing zero, one, two, three, and four pollen tubes was recorded. Pollen viability was expressed as tetrad germination (percentage of tetrads with at least one pollen tube). The mean number of pollen tubes per germinated tetrad was also calculated.

In order to determine total pollen production, flowers just prior to anthesis were sampled. Experimental units consisted of 30 flowers collected from the seven plants of each cultivar at each location. Flowers were detached with forceps and placed upright on the wells of a tissue culture plate. Plates were carried to the laboratory and stored in a refrigerator before flower dissection. The distal half of the tubular corolla and the style were removed so that pollen could be released directly into a $150-\mathrm{mL}$ sample container without interference from flower parts. A pair of toothpicks and a piece of double-coated adhesive tape were used to hang multiple flowers from their pedicels. Thus, flowers were stored at room temperature in a hanging position inside the sample container for several weeks. Blueberry anthers are poricidally dehiscent and require vibration for efficient pollen release (Buchmann, 1983; Cane and Payne, 1988); therefore, flowers were sonicated with a 512-Hz tuning fork (Indigo Instruments, Waterloo, Ont.). Sonication was repeated several times, until little or no pollen appeared to remain inside the dry anthers. The number of tetrads in the container was measured electronically using a particle counter. Tetrads were suspended in $10 \mathrm{~mL}$ of $70 \%$ ethanol, and then $130 \mathrm{~mL}$ of Isoton II (Coulter Electronics, Hialeah, Fla.) were added. Repeated $0.5-\mathrm{mL}$ aliquots of continuously stirred pollen suspension were counted with a Coulter (model ZB1; Coulter Electronics) counter using a $140-\mu \mathrm{m}$ aperture.

The experimental design was a split-plot with location as the main plot and cultivar as the subplot. Experimental units for both evaluations were sampled on three separate days, with two replications per treatment combination per day. Data were analyzed using PROC MIXED of SAS (SAS Institute, Cary, N.C.).

OvULE NUMBER AND POLLEN RELEASE. Ovule number and pollen release were estimated in 2004 using containerized blueberry plants similar to those described previously. Three plants of each cultivar received their chilling requirement under natural conditions and then were brought into a greenhouse at the Univ. of Georgia Griffin Campus to force bloom. Samples of 25 flowers per cultivar were collected and fixed in 7:3,95\% ethanol:acetic acid. Ovaries were dissected and ovules were counted under a dissecting microscope.

Pollen release was evaluated under greenhouse conditions for 'Brightwell' and 'Climax' only. Twenty-five flowers of each cultivar were collected $1 \mathrm{~d}$ after anthesis. Pollen was extracted by rolling a flower between the thumb and index finger until no additional pollen was released. Tetrads from individual flowers were collected into a 20-mLblood cell-counter vial (Labcon, Petaluma, Calif.) and counted using the previously described particle counter. Ovule number and pollen release data were compared among cultivars using one-way analysis of variance.

\section{Results and Discussion}

Pollen viability. Cultivar was the only significant main effect for in vitro tetrad germination (Table 1). Location had no effect on in vitro tetrad germination, nor did it interact with cultivar. Although tetrad germination varied among genotypes, values were $\geq 80 \%$ in all four cultivars. These results were similar to the mean percentage of stainable pollen previously reported for rabbiteye blueberry (Cockerham and Galleta, 1976). The viability results from this study were also similar to the level of pollen viability reported for southern highbush blueberry (V. corymbosum $\times$ spp.) cultivars (Lang and Parrie, 1992). The number of pollen tubes observed in germinated tetrads ranged from one to four. On average, germinated tetrads of all cultivars produced two pollen tubes per tetrad. These findings contrast with previous reports indicating that multiple pollen tubes per tetrad are infrequent in blueberry (Brewer and Dobson, 1969). According to Lang and Parrie (1992), the average number of pollen tubes per germinated tetrad ranged from 1.7 to 3.4 among southern highbush blueberry cultivars.

Total POLLEN PRODUCTION AND POLLEN-OVULE RATIO. Total pollen production per flower averaged 8434 tetrads across all cultivars. This is about three times higher than the number reported for V. myrtilloides (Reader, 1977). Total pollen production was affected by cultivar and location (Table 1). Pollen numbers in 'Brightwell', 'Climax', and 'Tifblue' were significantly higher than in 'Austin'. Additional research would be needed to confirm a location effect and to identify the environmental factors that may have an influence on pollen production. There was no location $\times$ cultivar interaction.

The mean number of ovules per flower ranged between 71 and 103 (Table 2). Tetrad and ovule numbers per flower estimated in 2002 and 2004, respectively, were used to calculate tetrad- 
Table 1. In vitro tetrad germination, number of pollen tubes per germinated tetrad, and total pollen tetrad production per flower in 'Austin', 'Brightwell', 'Climax', and 'Tifblue' rabbiteye blueberry from two locations.

\begin{tabular}{lccc}
\hline & $\begin{array}{c}\text { Tetrad } \\
\text { germination } \\
(\%)\end{array}$ & $\begin{array}{c}\text { Pollen tubes } \\
\text { per germinated } \\
\text { tetrad } \\
(\text { no. })\end{array}$ & $\begin{array}{c}\text { Total pollen } \\
\text { production } \\
\text { tetrads per } \\
\text { flower) }\end{array}$ \\
\hline $\begin{array}{l}\text { Location } \\
\text { Alapaha }\end{array}$ & $87.5 \mathrm{a}^{\mathrm{z}}$ & $2.0 \mathrm{a}$ & $7613 \mathrm{~b}$ \\
Griffin & $82.9 \mathrm{a}$ & $2.0 \mathrm{a}$ & $9254 \mathrm{a}$ \\
Cultivar & $80.8 \mathrm{~b}$ & $2.0 \mathrm{a}$ & $6638 \mathrm{~b}$ \\
Austin & $90.2 \mathrm{a}$ & $2.1 \mathrm{a}$ & $9213 \mathrm{a}$ \\
Brightwell & $88.4 \mathrm{a}$ & $2.0 \mathrm{a}$ & $9065 \mathrm{a}$ \\
Climax & $81.5 \mathrm{~b}$ & $2.0 \mathrm{a}$ & $8818 \mathrm{a}$ \\
Tifblue & & & $*$ \\
Significance & $\mathrm{NS}$ & $\mathrm{NS}$ & $* * *$ \\
Location (L) & $* *$ & $\mathrm{NS}$ & $\mathrm{NS}$ \\
Cultivar (C) & $\mathrm{NS}$ & $\mathrm{NS}$ & \\
L $\times$ C & & &
\end{tabular}

"Means were separated by LSD test at $P \leq 0.05$.

NS, *, **, ****Nonsignificant or significant at $P \leq 0.05,0.01$, or 0.001 , respectively.

Table 2. Number of ovules per flower, tetrad-to-ovule ratio, pollen grain-to-ovule ratio, and pollen release in four rabbiteye blueberry cultivars.

\begin{tabular}{lcccc}
\hline Cultivar & $\begin{array}{c}\text { Ovules per } \\
\text { flower } \\
\text { (no.) }\end{array}$ & $\begin{array}{c}\text { Tetrad: } \\
\text { ovule } \\
\text { ratio }^{\mathrm{z}}\end{array}$ & $\begin{array}{c}\text { Pollen: } \\
\text { ovule } \\
\text { ratio }^{\mathrm{z}}\end{array}$ & $\begin{array}{c}\text { Pollen release } \\
\text { (tetrads per } \\
\text { flower) }\end{array}$ \\
\hline Austin & $78 \mathrm{cy}$ & 85 & $340^{\mathrm{x}}$ & $---{ }^{\mathrm{w}}$ \\
Brightwell & $88 \mathrm{~b}$ & 105 & 419 & $8,339 \mathrm{a}^{\mathrm{y}}$ \\
Climax & $103 \mathrm{a}$ & 88 & 352 & $4,771 \mathrm{~b}$ \\
Tifblue & $71 \mathrm{~d}$ & 124 & 497 & --- \\
Mean \pm SE & $85 \pm 7$ & $101 \pm 9$ & $402 \pm 36$ & \\
\hline
\end{tabular}

$\overline{\text { Ratios were estimated based on overall means of tetrad production per }}$ flower. Tetrad production was evaluated in 2002 (Table 1). No. ovules per flower and pollen release were evaluated in 2004.

yMeans were separated by LSD test at $P \leq 0.05$.

xPollen grain-to-ovule ratio was calculated using the formula [(no. tetrads/flower $) \times(4$ pollen grains/tetrad $)] /$ (no. ovules/flower) .

wNot evaluated

to-ovule and pollen grain-to-ovule ratios. Rabbiteye blueberry cultivars had a pollen grain-to-ovule ratio of $\approx 400$. According to Cruden (1977), the pollen-ovule ratio of xenogamous species is $\approx 6000$. Clearly, pollen-to-ovule ratios in rabbiteye blueberry are much lower than in other flowering plants with similar breeding systems. It has been proposed that pollen-to-ovule ratios are inversely related to the likelihood of a pollen grain reaching the stigma (Cruden, 1977; Cruden and Jensen, 1979; Cruden and Lyon, 1989). Low pollen-to-ovule ratios in rabbiteye blueberry flowers indicate that pollen transfer might be more efficient than in other xenogamous entomophilous plants. Several aspects of the reproductive biology of blueberries support this idea. Blueberry flowers are adapted to buzz-pollination, which implies that their anthers are poricidal (apically dehiscent), and that sonication (bee-induced vibration of the androecium) is the most effective way to release pollen (Buchmann, 1983; Cane and Payne, 1988). Research has shown that poricidal anthers act as an efficient pollen dispensing mechanism, restricting removal per pollinator and controlling release according to the visitation rate (Harder and Barclay, 1994). Moreover, pollen grains in poricidal anthers are

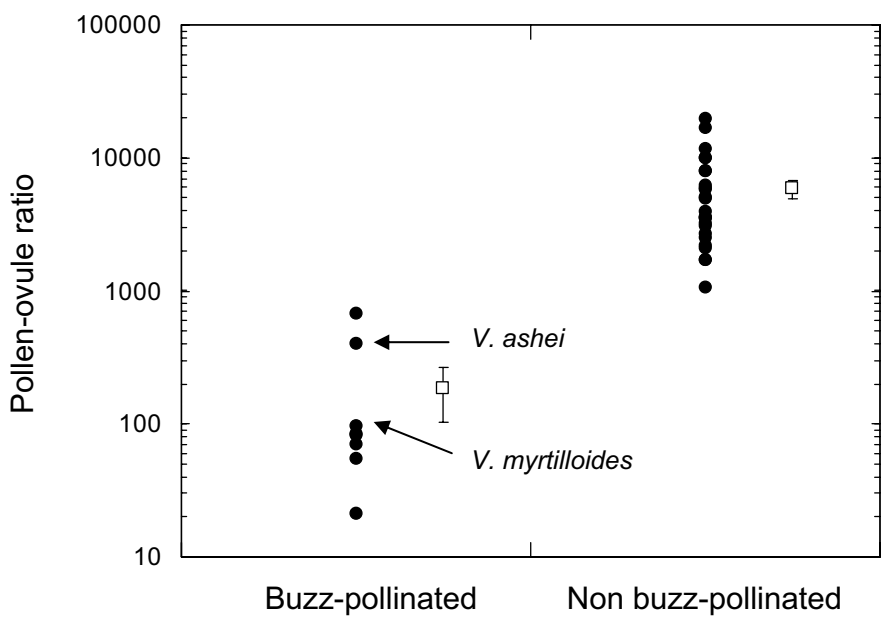

Fig. 1. Pollen-ovule ratios $(\bullet)$ in xenogamous species that are buzz-pollinated (n $=8)$ and non buzz-pollinated $(\mathrm{n}=24)$, based on a literature review. Mean $( \pm \mathrm{SE})$ pollen-ovule ratios for each group ( $\square$ ) are also presented. Buzz-pollinated species: Moneses uniflora (L.) A. Gray, Orthilia secunda (L.) House, Pyrola minor L., P. rotundifolia L., P. chlorantha Swartz (Knudsen and Olesen, 1993), Rhexia virginica L. (Larson and Barrett, 1999), Vaccinium myrtilloides [based on pollen and ovule numbers from Reader (1977) and Palser (1961)], and $V$. ashei (this study). Non buzz-pollinated species: 24 species from 10 families listed as xenogamous by Cruden (1977). These taxa are excluded from the list of poricidally dehiscent plants given by Buchmann (1983).

well protected from environmental hazards such as exposure to ultraviolet light and rain, as compared to those in longitudinally dehiscent anthers (Buchmann, 1983; Michener, 2000). The high efficiency of the pollen dispensing mechanism would justify a reduction in the pollen-ovule ratio of rabbiteye blueberries, relative to other xenogamous non-buzz pollinated species. Pollen-ovule ratios reported in other buzz-pollinated plants are also low, which further support this hypothesis (Fig. 1).

Previous studies have shown that species with pollen transporting mechanisms such as tetrads, polyads, and viscin threads have lower pollen-ovule ratios than species that simply release pollen as monads (Cruden, 1977; Cruden and Jensen, 1979; Vasek and Weng, 1988). The pollen dispersal unit for Vaccinium is a tetrad (Cockerham and Galleta, 1976; Stushnoff and Hough, 1968). This strategy also helps to explain the low pollen-ovule ratio of rabbiteye blueberry.

Pollen Release. 'Brightwell' flowers released almost twice as many tetrads as those of 'Climax' (Table 2), even though total pollen production per flower was similar in both cultivars (Table 1). Brewer and Dobson (1969) reported a similar difference between two highbush cultivars, although the regulatory mechanism responsible for this variation was not identified. In 'Brightwell' and 'Climax', the length and diameter of the anther tubes may have a direct or indirect effect on pollen release. Examination of 'Climax' stamens revealed longer, narrower anther tubes, relative to 'Brightwell' (Fig. 2). Anther tubes with such characteristics will likely offer a higher resistance to the flow of pollen, thus restricting its release. Pollen grains from poricidal anthers tend to form clumps due to either electrostatic interactions (Buchmann, 1983) or the presence of tapetal fluid (King and Ferguson, 1994). Therefore, narrow tubes would tend to clog more easily with these clumps. Alternatively, tube length and diameter may have an effect on the dehydration rate of pollen grains inside the anther locules. Shorter, wider tubes would allow better gas exchange, which would increase the rate of pollen dehydration. In poricidally dehiscent plants, pollen grains must be dry, smooth, and non-sticky for efficient release following 

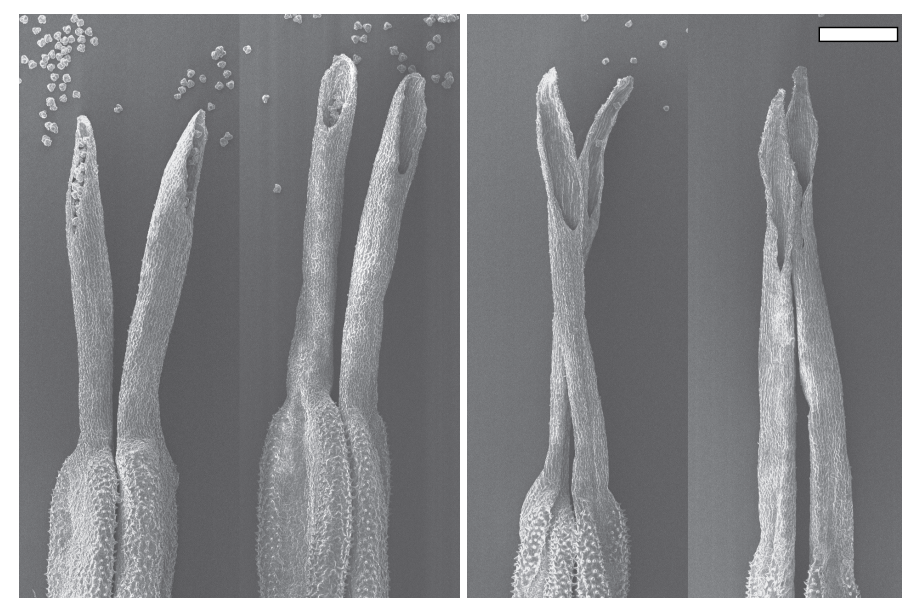

Fig. 2. Scanning electron micrographs of anther tubes from the rabbiteye blueberry cultivars Brightwell (left) and Climax (right). All micrographs are at the same scale. Scale bar: $0.5 \mathrm{~mm}$.

sonication (Buchmann and Hurley, 1978). Hence, it is suggested that these anther characteristics might account for differences in pollen release observed among cultivars.

In summary, in vitro tetrad germination was high $(\geq 80 \%)$ in all cultivars studied. Pollen viability does not seem to be a limiting factor for fruit set in rabbiteye blueberry. The low pollen-ovule ratio of rabbiteye blueberry is apparently an indicator of the high efficiency of its pollen dispensing mechanism, characterized by poricidally dehiscent anthers. A significant difference in pollen release was found between flowers of two cultivars with similar pollen production. Additional research is needed to establish if different propensities for pollen release can influence cultivar preferences by pollen-collecting bees.

\section{Literature Cited}

Bawa, K.S. and C.J. Webb. 1984. Flower, fruit and seed abortion in tropical forest trees: implications for the evolution of paternal and maternal reproductive patterns. Amer. J. Bot. 71:736-751.

Brewer J.W. and R.C. Dobson. 1969. Pollen analysis of two highbush blueberry varieties Vaccinium corymbosum. J. Amer. Soc. Hort. Sci. 94:251-252.

Buchmann, S.L. 1983. Buzz pollination in angiosperms, p. 73-113. In: C.E. Jones and R.J. Little (eds.). Handbook of experimental pollination biology. Van Nostrand Reinhold, New York.

Buchmann, S.L. and J.P. Hurley. 1978. A biophysical model for buzz pollination in angiosperms. J. Theor. Biol. 72:639-657.

Burd, M. 1994. Bateman's principle and plant reproduction: the role of pollen limitation in fruit and seed set. Bot. Rev. 60:83-139.

Cane, J.H. and J.A. Payne. 1988. Foraging ecology of the bee Habropoda laboriosa (Hymenoptera: Anthophoridae), an oligolege of blueberries (Ericaceae: Vaccinium) in the southeastern United States. Ann. Entomol. Soc. Amer. 81:419-427.

Cockerham, L.E. and G.J. Galleta. 1976. A survey of pollen characteristics in certain Vaccinium species. J. Amer. Soc. Hort. Sci. 101:671-676.

Cruden, R.W. 1977. Pollen-ovule ratios: A conservative indicator of breeding systems in flowering plants. Evolution 31:32-46.

Cruden, R.W. and K.G. Jensen. 1979. Viscin threads, pollination efficiency and low pollen-ovule ratios. Amer. J. Bot. 66:875-879.
Cruden, R.W. and D.L. Lyon. 1989. Facultative xenogamy: Examination of a mixed-mating system, p. 171-207. In: J. Bock and Y.B. Linhart (eds.). The evolutionary ecology of plants. Westview Press, Boulder, Colo.

Eaton, G.W. 1966. Production of highbush blueberry pollen and its germination in vitro as affected by $\mathrm{pH}$ and sucrose concentration. Can. J. Plant Sci. 46:207-209.

El-Agamy, S.Z.A., W.B. Sherman, and P.M. Lyrene. 1981. Fruit set and seed number from self- and cross-pollinated highbush $(4 \mathrm{x})$ and rabbiteye (6x) blueberries. J. Amer. Soc. Hort. Sci. 106:443-445.

Garvey, E.J. and P.M. Lyrene. 1987. Self incompatibility in 19 native blueberry selections. J. Amer. Soc. Hort. Sci. 112:856-858.

Goldy, R.G. and P.M. Lyrene. 1983. Pollen germination in interspecific Vaccinium hybrids. HortScience 18:54-55.

Harder, L.D. and R.M.R. Barclay. 1994. The functional significance of poricidal anthers and buzz pollination: Controlled pollen removal from Dodecatheon. Functional Ecol. 8:509-517.

Harder, L.D. and W.G. Wilson. 1997. Theoretical perspectives on pollination. Acta Hort. 437:83-101.

King, M.J. and A.M. Ferguson. 1994. Vibratory collection of Actinidia deliciosa (kiwifruit) pollen. Ann. Bot. 74:479-482.

Knudsen, J.T. and J.M. Olesen. 1993. Buzz-pollination and patterns in sexual traits in north European Pyrolaceae. Amer. J. Bot. 80:900-913.

Lang, G.A. and E.J. Parrie. 1992. Pollen viability and vigor in hybrid southern highbush blueberries (Vaccinium corymbosum L. $\times$ spp.). HortScience 27:425-427.

Larson, B.M.H. and S.C.H. Barrett. 1999. The pollination ecology of buzz-pollinated Rhexia virginica (Melastomataceae). Amer. J. Bot. 86:502-511.

Larson, B.M.H. and S.C.H. Barret. 2000. Acomparative analysis of pollen limitation in flowering plants. Biol. J. Linnean Soc. 69:503-520.

Lyrene, P.M. and T.E. Crocker. 1983. Poor fruit set on rabbiteye blueberries after mild winters: Possible causes and remedies. Proc. Fla. State Hort. Soc. 96:195-197.

Michener, C.D. 2000. The bees of the world. Johns Hopkins Univ. Press, Baltimore, $\mathrm{Md}$.

NeSmith, D.S. and H.M. Adair. 2004. Rabbiteye blueberry field trials with the growth regulator CPPU. Small Fruits Rev. 3(1/2):183-191.

Palser, B.F. 1961. Studies of floral morphology in the Ericales. V. Organography and vascular anatomy in several United States species of the Vacciniaceae. Bot. Gaz. 123:79-111.

Reader, R.J. 1977. Bog ericad flowers: Self-compatibility and relative attractiveness to bees. Can. J. Bot. 55:2279-2287.

Scherm, H., D.S. NeSmith, D.L. Horton, and G. Krewer. 2001. A survey of horticultural and pest management practices of the Georgia blueberry industry. Small Fruits Rev. 1(4):17-28.

Shutak V.G. and P.E. Marucci. 1966. Plant and fruit development, p. 179-198. In: P.Eck and N.F. Childers (eds.). Blueberry culture. Rutgers Univ. Press. New Brunswick, N.J.

Sutherland, S. 1987. Why hermaphroditic plants produce many more flowers than fruits: Experimental tests with Agave mckelveyana. Evolution 41:750-759.

Stushnoff, C. and L.F. Hough. 1968. Sporogenesis and gametophyte development in 'Bluecrop' and 'Coville' highbush blueberries. Proc. Amer. Soc. Hort. Sci. 93:242-247.

Thorp, R.W. 2000. The collection of pollen by bees. Plant Syst. Evol. 222:211-223.

Vander Kloet, S.P. 1983. The relationship between seed number and pollen viability in Vaccinium corymbosum L. HortScience 18:225-226.

Vasek, F.C. and V. Weng. 1988. Breeding systems of Clarkia sect. Phaeostoma (Onagraceae): I. Pollen-ovule ratios. Systematic Bot. 13:336-350. 